\title{
Bortezomib-Induced Multiple Chalazia: A Case Report
}

\author{
Rania Mohamed1, Horace Massa², Claude Schwarz², Nicole Grandjean-Hallez \\ Kaveh Samii ${ }^{1}$ \\ ${ }^{1}$ Hematology Department, University of Geneva Hospitals, Geneva, Switzerland \\ ${ }^{2}$ Ophtalmology Department, University of Geneva Hospitals, Geneva, Switzerland \\ ${ }^{3}$ Oncology Department, University of Geneva Hospitals, Geneva, Switzerland \\ Email: rania.mohamed@hcuge.ch
}

Received 27 December 2014; accepted 11 January 2015; published 19 January 2015

Copyright (C) 2015 by authors and Scientific Research Publishing Inc.

This work is licensed under the Creative Commons Attribution International License (CC BY).

http://creativecommons.org/licenses/by/4.0/

c) (i) Open Access

\begin{abstract}
Bortezomib is a novel agent for the treatment of patients with multiple myeloma. Several cutaneous lesions have been associated with its use and chalazia have been reported in a few cases with a delayed appearance ranging from 1 to 6 months. We describe the case of a 59-year-old man with multiple myeloma IgG kappa, ISS2, who developed a chalazion induced by bortezomib. Following the failure of conservative treatment, a biopsy was performed to exclude extramedullary plasmocytoma. Bortezomib was discontinued due to the persistence of lesions and a therapeutic approach combining systemic antibiotics with incision and curettage was adopted. An active inflammatory lesion developed after 1 month, similar to that observed under bortezomib therapy. Symptoms resolved only 5 months later and the patient remained free of any ocular manifestation. Physicians should be aware that chalazia may be resistant to conventional treatment and lead to local complications, such as cellulitis.
\end{abstract}

\section{Keywords}

Bortezomib, Chalazion, Meibomian Gland

\section{Introduction}

Chalazion [1], also known as a meibomian gland lipogranuloma, is caused by the inflammation of a blocked meibomian gland and retained secretions. Fluid accumulates in the gland, which ruptures and releases lipids into the surrounding tissues, causing a granulomatous inflammatory reaction. Fluid may become infected, with the appearance of a red and painful swollen cyst. These cysts can persist as they are trapped in the fibrous skeleton 
of the lid. Patients usually display lid swelling, pain and symptoms of local irritation. It is a benign and often self-limiting reaction and affects more frequently the upper eyelid. Chalazia often disappear without further treatment within a few months. However, larger lesions may be unsightly and may lead to complications, such as corneal astigmatism, mechanical ptosis, and secondary infections, such as cellulitis.

In recent years, novel agents, such as bortezomib [2]-[4], have changed the management of multiple myeloma. Bortezomib, a modified dipeptidyl boronic acid, is a selective and reversible inhibitor of the 26S proteasome, leading to cell death. The most common adverse effect reported is diarrhea, which may lead sometimes to discontinuation of treatment. Other reported side-effects are peripheral neuropathy, neutropenia, thrombocytopenia, infections, cardiac events and gastrointestinal disturbances. We report herein the case of bortezomib-induced chalazia, resistant to treatment in a patient with multiple myeloma.

\section{Case Report}

A 59-year-old male patient diagnosed with stage II ISS IgG lambda multiple myeloma was treated with 3 cycles of bortezomib (1.3 mg/m $\mathrm{m}^{2}$ on days $1,4,8$ and 11), cyclophosphamide $\left(500 \mathrm{mg} / \mathrm{m}^{2}\right.$ on days 1 and 8$)$, and dexamethasone (40 mg/day) every 21 days. He then received 4 cycles of bortezomib $\left(1.3 \mathrm{mg} / \mathrm{m}^{2}\right)$, melphalan (9 $\mathrm{mg} / \mathrm{m}^{2}$ ), and prednisone $\left(60 \mathrm{mg} / \mathrm{m}^{2}\right.$ ) (VMP) every 42 days. During the second cycle, the patient developed a painless, erythematous swelling on the upper eyelid. The lesion was firm and nodular and a clinical diagnosis of chalazion was retained. The evolution was unfavorable with persistence of the lesion. The patient then developed a second chalazion on the upper right eyelid (Figure 1). Thereafter, two eyelids were affected with pus discharge when pressure was applied to the lesion. Bortezomib was discontinued. However, a new chalazia lesion developed 1 month later. A biopsy excluded plasmocytoma infiltration and sebaceous cell carcinoma. Conservative treatment was started as the first line of management, i.e., topical antibiotic eye drops or ointment for the initial acute infection, followed by the application of warm compresses to the affected eye to promote drainage and healing by softening the hardened oil occluding the duct. However, this treatment failed and multiple chalazia developed. Due to local complications, an approach combining systemic antibiotics with incision and curettage was adopted. Bortezomib was discontinued given the persistence of lesions. One month later, an inflammatory active lesion appeared as during bortezomib therapy. Symptoms resolved only 5 months later and the patient remains free of any eye manifestation. Bortezomib was not rechallenged, and other therapeutic agents were then used for treatment.

\section{Discussion}

Bortezomib is a highly selective and reversible proteasome inhibitor approved for the treatment of multiple myeloma, but it remains under investigation in more extensive clinical trials for other malignancies. The most common adverse events are gastrointestinal symptoms (diarrhea, nausea, constipation, and vomiting), fatigue, and peripheral neuropathy [5]. Thrombocytopenia, hypotension, fever, headache, pain, and deshydratation are other adverse effects reported. Skin lesions due to bortezomib have been mostly described as purpuric rashes in $8 \%-18 \%$ of cases (vasculitis-like rash) [6]-[11]. There are few reports of bortezomib-induced chalazia and we found only six cases of chalazia secondary to bortezomib therapy reported in the literature [12]. Similar to our
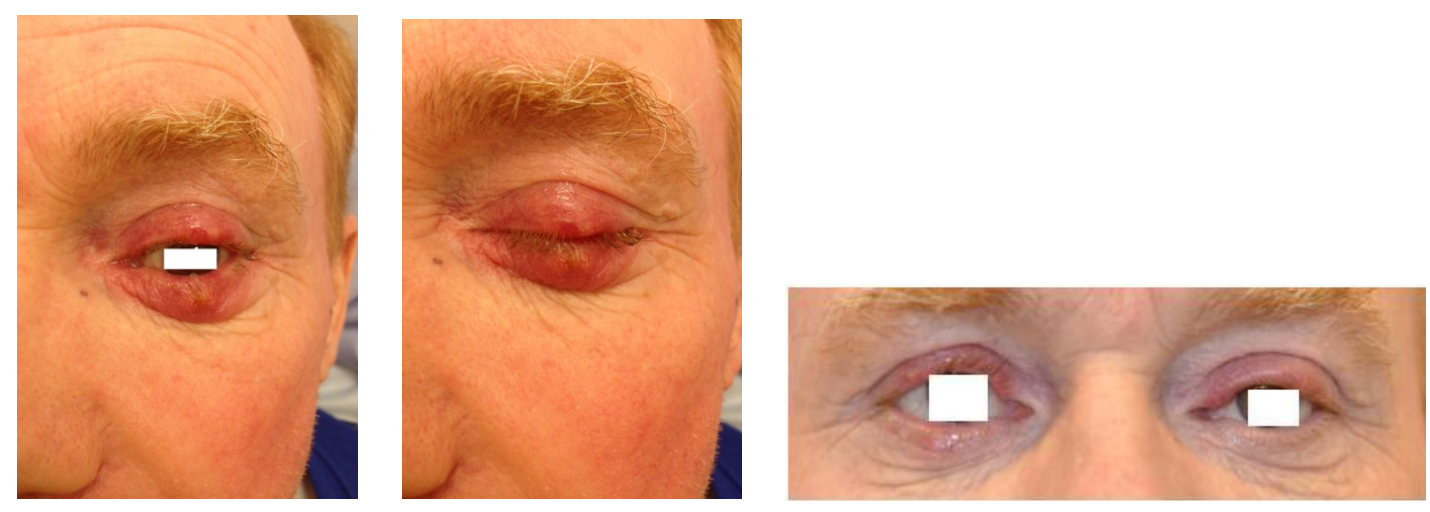

Figure 1. From left to right: Chalazion of left opened eye; Chalazion of left closed eye; Chalazia of both eyes. 
patient, these cases developed multiple large chalazia affecting multiple eyelids with no response to conservative treatment. However, the pathogenesis of chalazia in this setting remains unclear.

The mechanism of the anti-cancer activity of bortezomib is still not completely understood. Recently, it was shown to activate the unfolded protein response and endoplasmic reticulum stress-associated apoptosis by inhibiting the 26S proteasome. The endoplasmic reticulum is the cellular organelle responsible for protein folding and assembly, lipid and sterol biosynthesis, and calcium storage. The unfolded protein response is an adaptive intracellular stress response to the accumulation of unfolded or misfolded proteins in the endoplasmic reticulum. Zhang and al demonstrated that the administration of bortezomib to mice induced an endoplasmic reticulum stress that led to severe hepatic steatosis [13]. As chalazia results from a deposition and release of lipids, we propose the hypothesis that the mechanism could be similar to hepatic steatosis.

\section{Conclusion}

We recommend that clinicians address patients to an ophthalmologist if eye lesions appear under bortezomib treatment, due to the risk of local complications. These lesions are often refractory to conservative management and can persist after bortezomib discontinuation.

\section{Conflict of Interest}

The authors declare that they have no conflict of interest.

\section{References}

[1] Wojtowicz, J.C., Butovich, I.A., McMahon, A., Hogan, R.N., Itani, K.M., Mancini, R., Molai, M. and Linsenbardt, E. (2014) Time-Dependent Degenerative Transformations in the Lipidome of Chalazia. Experimental Eye Research, 127, 261-269. http://dx.doi.org/10.1016/j.exer.2014.08.008

[2] Mateos, M.V., Hernandez, J.M., Hernandez, M.T., Gutierrez, N.C., Palomera, L., Fuertes, M., Garcia-Sanchez, P., Lahuerta, J.J., de la Rubia, J., Terol, M.J., Sureda, A., Bargay, J., Ribas, P., Alegre, A., de Arriba, F., Oriol, A., Carrera, D., Garcia-Larana, J., Garcia-Sanz, R., Blade, J., Prosper, F., Mateo, G., Esseltine, D.L., van de Velde, H. and San Miguel, J.F. (2008) Bortezomib plus Melphalan and Prednisone in Elderly Untreated Patients with Multiple Myeloma: Updated Time-to-Events Results and Prognostic Factors for Time to Progression. Haematologica, 93, 560-565. http://dx.doi.org/10.3324/haematol.12106

[3] Mateos, M.V., Hernandez, J.M., Hernandez, M.T., Gutierrez, N.C., Palomera, L., Fuertes, M., Diaz-Mediavilla, J., Lahuerta, J.J., de la Rubia, J., Terol, M.J., Sureda, A., Bargay, J., Ribas, P., de Arriba, F., Alegre, A., Oriol, A., Carrera, D., Garcia-Larana, J., Garcia-Sanz, R., Blade, J., Prosper, F., Mateo, G., Esseltine, D.L., van de Velde, H. and San Miguel, J.F. (2006) Bortezomib plus Melphalan and Prednisone in Elderly Untreated Patients with Multiple Myeloma: Results of a Multicenter Phase 1/2 Study. Blood, 108, 2165-2172. http://dx.doi.org/10.1182/blood-2006-04-019778

[4] Richardson, P.G., Barlogie, B., Berenson, J., Singhal, S., Jagannath, S., Irwin, D., Rajkumar, S.V., Srkalovic, G., Alsina, M., Alexanian, R., Siegel, D., Orlowski, R.Z., Kuter, D., Limentani, S.A., Lee, S., Hideshima, T., Esseltine, D.L., Kauffman, M., Adams, J., Schenkein, D.P. and Anderson, K.C. (2003) A Phase 2 Study of Bortezomib in Relapsed, Refractory Myeloma. New England Journal of Medicine, 348, 2609-2617. http://dx.doi.org/10.1056/NEJMoa030288

[5] Richardson, P.G., Briemberg, H., Jagannath, S., Wen, P.Y., Barlogie, B., Berenson, J., Singhal, S., Siegel, D.S., Irwin, D., Schuster, M., Srkalovic, G., Alexanian, R., Rajkumar, S.V., Limentani, S., Alsina, M., Orlowski, R.Z., Najarian, K., Esseltine, D., Anderson, K.C. and Amato, A.A. (2006) Frequency, Characteristics, and Reversibility of Peripheral Neuropathy during Treatment of Advanced Multiple Myeloma with Bortezomib. Journal of Clinical Oncology, 24, 3113-3120. http://dx.doi.org/10.1200/JCO.2005.04.7779

[6] Agterof, M.J. and Biesma, D.H. (2005) Images in Clinical Medicine. Bortezomib-Induced Skin Lesions. New England Journal of Medicine, 352, 2534. http://dx.doi.org/10.1056/NEJMicm041166

[7] Pour, L., Hajek, R., Zdenek, A., Krejci, M., Krivanova, A. and Vorlicek, J. (2005) Skin Lesions Induced by Bortezomib. Haematologica, 90, ECR44.

[8] Min, C.K., Lee, S., Kim, Y.J., Eom, K.S., Lee, J.W., Min, W.S., Kim, C.C., Cho, C.S. and Park, G. (2006) Cutaneous Leucoclastic Vasculitis (LV) Following Bortezomib Therapy in a Myeloma Patient; Association with Pro-Inflammatory Cytokines. European Journal of Haematology, 76, 265-268. http://dx.doi.org/10.1111/j.0902-4441.2005.t01-1-EJH2437.x

[9] Truchuelo, M., Bagazgoitia, L., Alcantara, J., Velasco, D. and Carrillo, R. (2012) Sweet-Like Lesions Induced by Bor- 
tezomib: A Review of the Literature and a Report of 2 Cases. Actas Dermo-Sifiliograficas, 103, 829-831. http://dx.doi.org/10.1016/j.ad.2012.03.002

[10] Wu, K.L., Heule, F., Lam, K. and Sonneveld, P. (2006) Pleomorphic Presentation of Cutaneous Lesions Associated with the Proteasome Inhibitor Bortezomib in Patients with Multiple Myeloma. Journal of the American Academy of Dermatology, 55, 897-900. http://dx.doi.org/10.1016/j.jaad.2006.06.030

[11] Patrizi, A., Venturi, M., Dika, E., Maibach, H., Tacchetti, P. and Brandi, G. (2014) Cutaneous Adverse Reactions Linked to Targeted Anticancer Therapies Bortezomib and Lenalidomide for Multiple Myeloma: New Drugs, Old Side Effects. Cutaneous and Ocular Toxicology, 33, 1-6. http://dx.doi.org/10.3109/15569527.2013.787086

[12] Grob, S.R., Jakobiec, F.A., Rashid, A. and Yoon, M.K. (2014) Chalazia Associated with Bortezomib Therapy for Multiple Myeloma. Ophthalmology, 121, 1845-1847. http://dx.doi.org/10.1016/j.ophtha.2014.04.021

[13] Zhang, K., Wang, S., Malhotra, J., Hassler, J.R., Back, S.H., Wang, G., Chang, L., Xu, W., Miao, H., Leonardi, R., Chen, Y.E., Jackowski, S. and Kaufman, R.J. (2011) The Unfolded Protein Response Transducer IRE1 Alpha Prevents ER Stress-Induced Hepatic Steatosis. EMBO Journal, 30, 1357-1375. http://dx.doi.org/10.1038/emboj.2011.52 
Scientific Research Publishing (SCIRP) is one of the largest Open Access journal publishers. It is currently publishing more than 200 open access, online, peer-reviewed journals covering a wide range of academic disciplines. SCIRP serves the worldwide academic communities and contributes to the progress and application of science with its publication.

Other selected journals from SCIRP are listed as below. Submit your manuscript to us via either submit@scirp.org or Online Submission Portal.
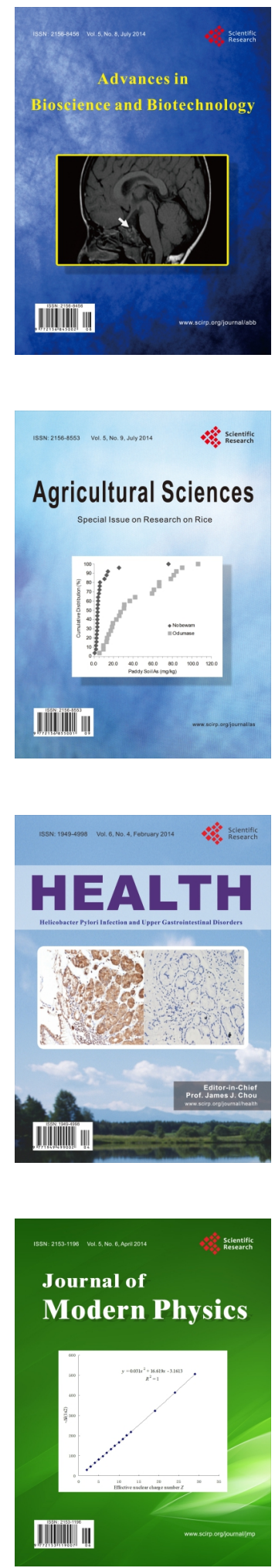
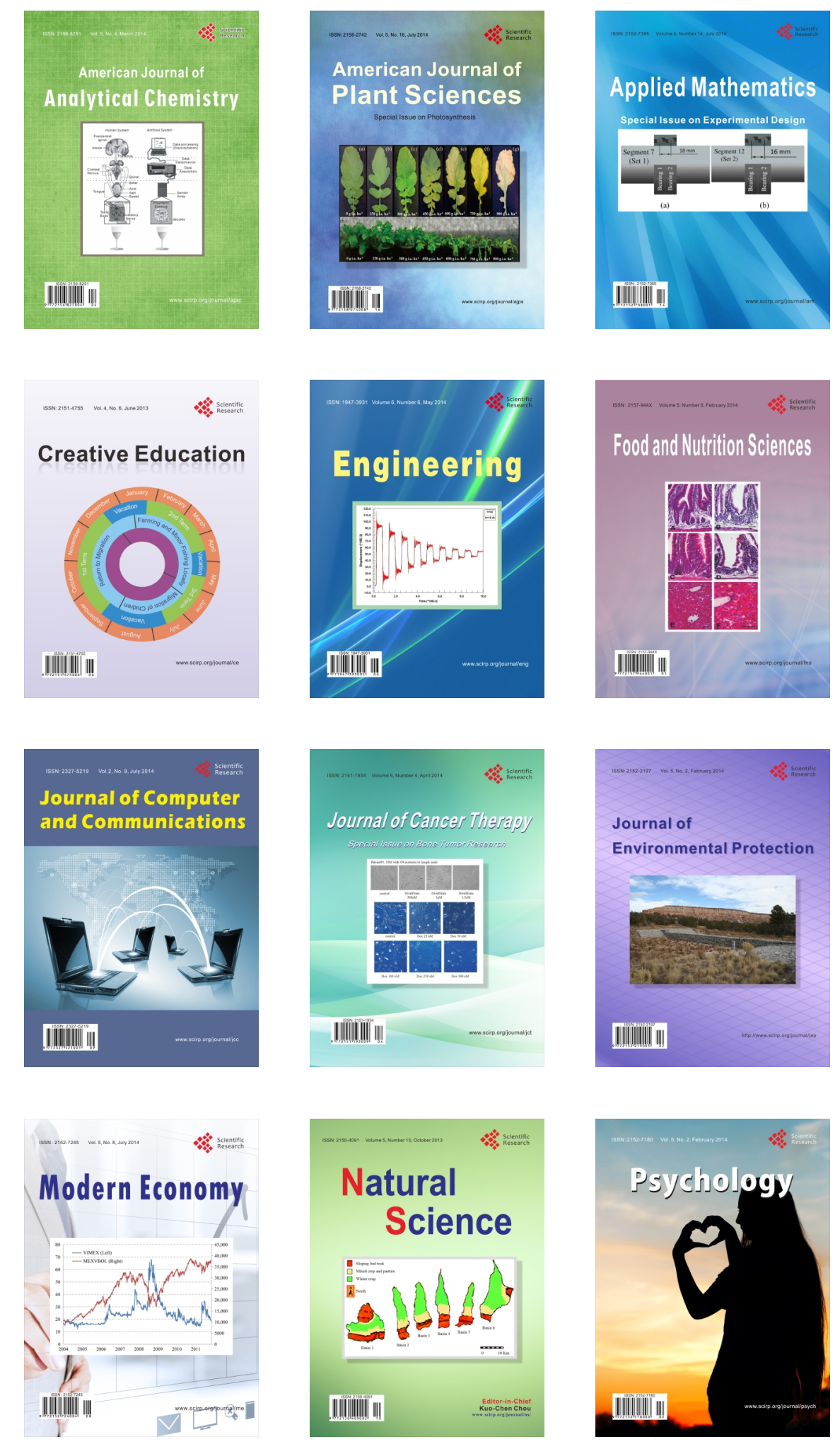